\title{
Erratum to: Crescent shaped braces for the seismic design of building structures
}

Michele Palermo - Stefano Silvestri •

Giada Gasparini · Tomaso Trombetti

Published online: 29 December 2015

(C) RILEM 2015

Erratum to: Materials and Structures (2015) 48:1485-1502

DOI 10.1617/s11527-014-0249-z

$$
\xi=1.5 \frac{E \cdot h \cdot \overline{F_{y}}}{\bar{K} \cdot L^{2} \cdot f_{y}} \cdot\left(\sqrt{1+5.33 \cdot(i / h)^{2} \cdot \frac{\bar{K} \cdot L}{E} \cdot \frac{f_{y}}{\overline{F_{y}}}}\right)
$$

Unfortunately, there are mistakes in Eq. (19). The corrected equation is given here:

The online version of the original article can be found under doi:10.1617/s11527-014-0249-z.

M. Palermo · S. Silvestri $(\bowtie) \cdot$ G. Gasparini ·

T. Trombetti

Department DICAM, University of Bologna, Viale

Risorgimento 2, 40136 Bologna, Italy

e-mail: stefano.silvestri@unibo.it 